\title{
DRENAJE ÁCIDO DE ROCAS EN TALUDES DE LA RUTA NACIONAL 27, SAN JOSÉ - CALDERA, COSTA RICA
}

\author{
ACID ROCK DRAINAGE ON SLOPES FROM ROUTE 27 \\ SAN JOSÉ - CALDERA, COSTA RICA
}

\author{
Paulo Ruiz ${ }^{1,2 *}$, Alejandro Arauz², Jairo Garcia², Giorghi Villalobos², \\ Ariel Sedó ${ }^{2}$ \& Carolina Suárez ${ }^{2}$ \\ ${ }^{1}$ Laboratorio Nacional de Materiales y Modelos Estructurales \\ (LANAMME-UCR), Universidad de Costa Rica \\ ${ }^{2}$ Escuela Centroamericana de Geología, Universidad de Costa Rica \\ *Autor para contacto: paulo.ruizcubillo@ucr.ac.cr
}

(Recibido: 26/04/2015; aceptado: 15/09/2015)

\begin{abstract}
This study focuses on determinate the presence of acid rock drainage (ARD) on two slopes on Route27, Costa Rica, by analysis of paste $\mathrm{pH}$ and geochemistry of superficial water. The laboratory results (samples with $\mathrm{pH}$ up to 1.5), and the physical evidence observed in the field, shows that in fact there is ARD in some slopes. The ARD on the route is directly affecting the chemical and physical properties of the shotcrete on the slopes, welded steel and ditch for the surface water management, causing its collapse and creating a hazard for users. The importance of identify this chemical and physical process that is weathering the materials of the slopes in the road cuts, it's essential for the right corrective action and resolve the problem or at least minimize the negative effects and their influence on slope instability of the route.
\end{abstract}

Keywords: Acid drainage, hydrothermal alteration, paste $\mathrm{pH}$, geochemistry, route 27, Caldera.

\begin{abstract}
RESUMEN: Este trabajo se enfoca en determinar, mediante análisis de laboratorio de $\mathrm{pH}$ en pasta y geoquímica de aguas superficiales, la existencia de drenaje de ácido de rocas (DAR) en dos taludes de la Ruta Nacional 27, Costa Rica. Los resultados de laboratorio (muestras con pH de hasta 1,5), así como las evidencias físicas observadas en el campo, muestran que efectivamente esta carretera presenta DAR en algunos de sus taludes. El DAR en la ruta está afectando directamente las propiedades químicas y físicas del concreto lanzado que se colocó sobre los taludes, el acero electrosoldado y las cunetas para el manejo de aguas superficiales, ocasionando su colapso y generando un peligro para los usuarios. La importancia de identificar este proceso químico y físico que está alterando los materiales de los taludes en los cortes de la carretera, es fundamental para plantear las medidas correctivas adecuadas y resolver el problema, o al menos minimizar los efectos negativos y su influencia en la inestabilidad de taludes de la ruta.
\end{abstract}

Palabras clave: Drenaje ácido, alteración hidrotermal, pH en pasta, geoquímica, ruta 27, Caldera. 


\section{INTRODUCCIÓN}

Una de las tareas primordiales de los geólogos e ingenieros de carreteras, es poder identificar cuáles son los procesos químicos y físicos que alteran y transforman las rocas y suelos de taludes en los cortes de carreteras para poder plantear las medidas correctivas adecuadas y resolver el problema, o al menos minimizar los efectos negativos que generan estos fenómenos en la estabilidad de estos taludes.

La Ruta Nacional No 27 (RN-27) de Costa Rica, que comunica el Valle Central con la costa pacífica del país, es vital para el desenvolvimiento económico del país por lo que sus taludes deben estar bien caracterizados y presentar un nivel alto de seguridad para los usuarios. Sin embargo, durante su construcción y posterior inauguración en el año 2010, esta ruta ha presentado problemas de estabilidad en varios sectores, que han sido asociados con sitios donde se identificaron rocas afectadas por alteración hidrotermal (ACG, 2010; Porras et al., 2012; UGERVN, 2014). Sin embargo, como se muestra en este trabajo, los problemas de estabilidad de algunos de los taludes de la RN-27 van más allá de la alteración hidrotermal y es muy probable que las características mecánicas actuales de las rocas de la zona estén directamente asociadas con un proceso llamado "drenaje ácido de roca" (DAR).

Con el objetivo de verificar la presencia de DAR en las unidades litológicas en ciertos puntos de esta carretera, se empleó la metodología de $\mathrm{pH}$ en pasta (Sobek et al., 1978) y así identificar el impacto que este pueda tener sobre la infraestructura de la carretera.

\section{Ubicación de la zona de estudio}

El área de estudio se ubica entre Escobal y Orotina sobre la $\mathrm{RN}-27$, en el tramo entre los estacionamientos de los kilómetros 45+600 y $48+000$, que se encuentra entre los puentes de la quebrada Concepción y el río Salitral. La altitud de los sitios analizados según el modelo de elevación digital (MED) generado es de entre 210 y 325 m s.n.m. (Fig. 1). Dentro de la clasificación de zonas de vida de Holdridge para Costa Rica (Holdridge, 1967), la zona de estudio corresponde con un Bosque Húmedo Tropical (bh-T) donde las temperaturas superan los $24^{\circ} \mathrm{C}$ la mayor parte del año, hay un promedio anual de lluvia de entre 1800 y 4000 mm, y presenta una estación seca bien marcada que puede extenderse hasta por cinco meses, usualmente entre diciembre y abril-mayo.

La geomorfología de este sector corresponde con una zona montañosa con laderas denudacionales de origen volcánico con pendientes altas, moderadas y bajas con ángulos que varían entre $8^{\circ}$ y $35^{\circ}$. Las pendientes más altas favorecen los procesos denudacionales intensos (deslizamientos) y también son susceptibles a la erosión de suelos. La cobertura vegetal es posible, pero se dificulta una vez que ocurren deslizamientos ya que la pendiente usualmente se incrementa en las zonas afectadas y los suelos quedan descubiertos y más propensos a escorrentía. En la margen izquierda del río Grande de Tárcoles existe un plateau ignimbrítico que presenta pendientes muy bajas $<10^{\circ}$. El patrón de drenaje en la zona de estudio es de tipo dendrítico con los valles fluviales poco desarrollados en los ríos que son afluentes al Grande Tárcoles que presenta un cañón con sinuosidad moderada y pendientes altas $\left(35-55^{\circ}\right)$ y en algunos casos muy altas $>55^{\circ}$ (Fig. 2). Los cortes realizados por el trazado de la $\mathrm{RN}-27$ han generado pendientes muy fuertes, en algunos casos con ángulos $>55^{\circ}$, como se describen más adelante. Además los materiales que fueron removidos durante la construcción de la ruta forman conos de talus en las zonas de escombreras.

\section{METODOLOGÍA}

Mediante visitas de campo se identificaron las zonas con taludes expuestos en la RN-27, que mostraban indicios de alteración hidrotermal arcillosa y la presencia de precipitados ferruginosos en los taludes rocosos, cunetas y concreto lanzado. Basados en esta selección y las condiciones 




Sistema de coordenadas: CRTM05 Fuente: Curvas 1: 25000 Proyecto Terra

Fig. 1: Ubicación del área de estudio sobre un MED con altitud. En el sitio del estacionamiento km 46+600 se tomaron en su mayoría muestras de rocas, mientras que en el sitio del estacionamiento km 48+000 se tomaron en su mayoría muestras de suelo.

para poder trabajar con seguridad sin afectar el tránsito de la vía, se definieron dos áreas de muestreo. La primera se estableció en el estacionamiento del kilómetro 45+600, el cual se definió para la toma de muestras de roca. La segunda zona de muestreo se estableció sobre el estacionamiento del kilómetro 48+000, que se definió para la toma de muestras de suelo, donde fue realizado un muestreo general y uno a detalle, a su vez para ambos se realizaron análisis in situ (Fig. 1).

\section{Muestreo de estacionamiento kilómetro 45+600}

El muestreo en este sitio fue realizado en el mes de mayo del 2014, estableciendo dos segmentos de trabajo, uno al lado derecho (LD) y otro al lado izquierdo (LI) de la carretera en el sentido San José-Caldera. A lo largo de estos dos tramos se tomaron 37 muestras de roca de al menos 15 cm de diámetro. Cada muestra fue tomada a una 


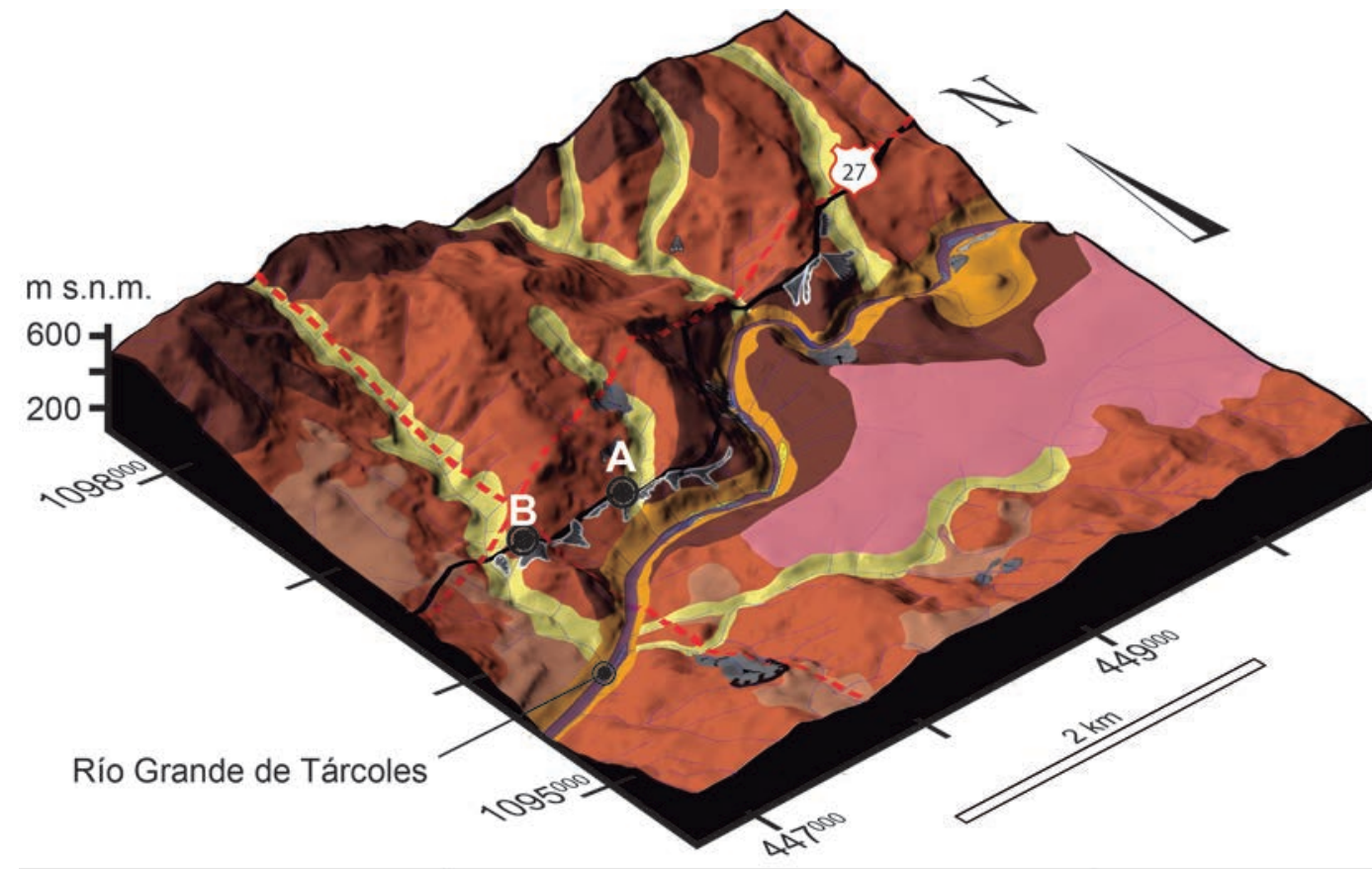

UNIDADES GEOMORFOLÓGICAS

Laderas denudacionales de origen volcánico

Denudacional pendiente alta $>35^{\circ}$

Denudacional de pendiente moderada $35-15^{\circ}$

Denudacional de pendiente baja $<15^{\circ}$

\section{Formas de origen volcánico pendiente muy baja $<10^{\circ}$}



27 Ruta Nacional 27

\section{Plateau ignimbrítico}

\section{Formas de origen fluvial}

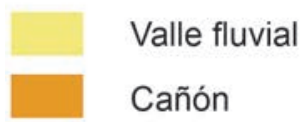

\section{Sistema de coordenadas: CRTM05 Fuente: Curvas 1: 25000 Proyecto Țerra}

Fig. 2: Aparecen los sitios muestreados (A) estacionamiento km 46+600 y (B) estacionamiento km 48+000 sobre un MED con información geomorfológica de la zona de estudio, se observa cómo en general la RN-27 atraviesa una zona de laderas denudacionales de origen volcánico con pendientes moderadas 16-35², paralelo al cañón del río Grande de Tárcoles.

distancia mínima de $\sim 5 \mathrm{~m}$ entre una y otra, a lo largo de $200 \mathrm{~m}$ y a ambos lados de la carretera (Fig. 3). A cada una de las muestras tomadas, se le realizó una descripción litológica macroscópica, se determinó el porcentaje de sulfuros de la muestra y la presencia de carbonatos mediante la utilización del $\mathrm{HCl}$ al $10 \%$. Además se tomaron fotografías de cada uno de los puntos en donde se substrajo cada muestra. Cada una de ellas se rotuló con un código específico y se 

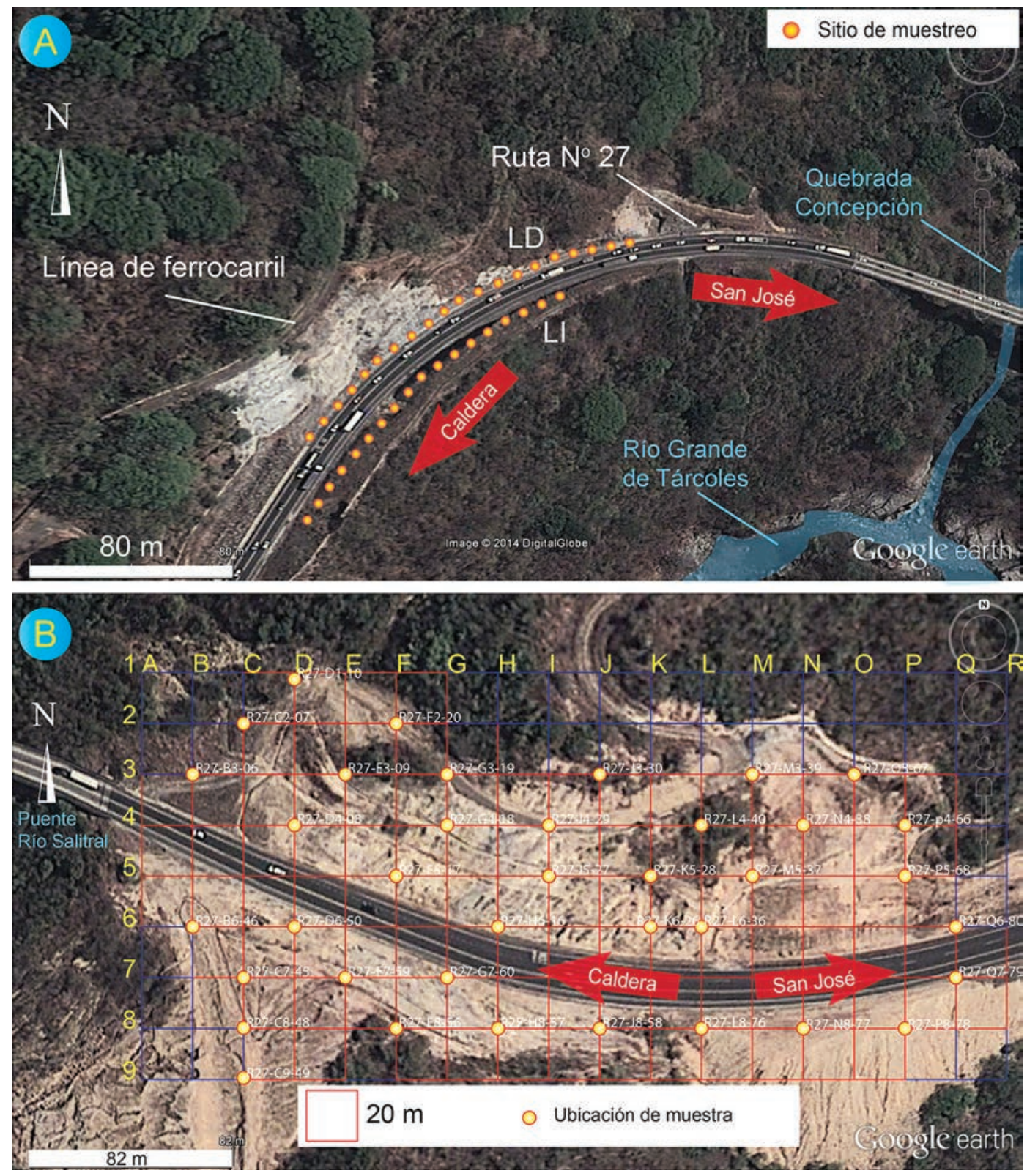

Fig. 3: Imágenes tomadas de Google Earth ${ }^{\circledR}$ A) Ubicación del sitio donde se tomaron las muestras de roca para análisis de pH en pasta. Talud con una pendiente general $>55^{\circ}$ e incluso casi vertical en algunos puntos, presenta dimensiones de $120 \mathrm{~m}$ de largo y $14 \mathrm{~m}$ de alto, además presenta diferentes tonalidades de color rojo, amarillo y anaranjado típicas de la oxidación de sulfuros y óxidos de hierro. $\mathrm{LD}=$ Lado derecho, $\mathrm{LI}=$ Lado izquierdo. B) Ubicación del sitio donde se tomaron las muestras de suelo en el estacionamiento 48+000, los taludes a ambos lados de la carretera presentan material muy disgregado con diferentes tonalidades (rojizas amarillentas) y grados de alteración (desde poco alterada hasta completamente alterada). 


\section{Cuadro 1}

Composición petrográfica de muestras de roca tomadas en la zona de estudio

\begin{tabular}{|c|c|c|c|c|}
\hline $\begin{array}{c}\text { Código/ } \\
\text { Estacionamiento }\end{array}$ & $\begin{array}{l}\text { Coordenadas- } \\
\text { CRTM-2005 }\end{array}$ & Descripción microscópica & Clasificación & $\begin{array}{c}\text { Formación } \\
\text { geológica }\end{array}$ \\
\hline $\mathrm{R} 27-1 / 48+000$ & $\begin{array}{c}447638,535 \mathrm{E} \\
1096562,815 \mathrm{~N}\end{array}$ & $\begin{array}{l}\text { Textura holocristalina porfirítica. Matriz }(72 \%) \text {, } \\
\text { recristalizada compuesta de cuarzo secundario, } \\
\text { arcillas, óxidos de hierro y opacos. Fenocristales } \\
(23 \%) \text {, plagioclasa ( } 13 \%) \text { hipidiomórfica, opacos } \\
(5 \%) \text {, anfíboles ( } 5 \%) \text { alterados a arcillas. Mine- } \\
\text { rales de alteración: cuarzo secundario (rellenando } \\
\text { cavidades), arcillas (altera feldespatos y ferromag- } \\
\text { nesianos), óxidos de hierro, sericita, ceolita y epi- } \\
\text { dota }(<1 \%) \text {. Otros rasgos: vesículas ( } 2 \%) \text {, amígda- } \\
\text { las }(3 \%) \text {, vetillas de arcillas y microfracturas. }\end{array}$ & Andesita recristalizada & Grifo Alto \\
\hline $\mathrm{R} 27-2 / 48+000$ & $\begin{array}{c}447608,115 \mathrm{E} \\
1096593,572 \mathrm{~N}\end{array}$ & $\begin{array}{l}\text { Textura holocristalina porfiritica. Matriz }(73 \%) \text {, } \\
\text { recristalizada compuesta de cuarzo secundario, } \\
\text { arcillas, óxidos de hierro y opacos. Fenocristales } \\
(25 \%) \text {, plagioclasa (18\%) hipidiomórficas, opacos } \\
\text { ( } 2 \%) \text {, ferromagnesianos alterados (5\%) con olivi- } \\
\text { nos alterados a serpentina y arcilla. Minerales de } \\
\text { alteración: calcita, sericita (alterando feldespa- } \\
\text { tos), cuarzo secundario (rellenando cavidades), } \\
\text { óxidos de hierro, arcillas, serpentina (alterando } \\
\text { olivino), titanita (traza). Otros rasgos: amígdalas } \\
(2 \%) \text { rellenas de filosilicatos o calcita. }\end{array}$ & Andesita recristalizada & Grifo Alto \\
\hline $\mathrm{R} 27-5 / 48+000$ & $\begin{array}{c}447638,623 \mathrm{E} \\
1096624,253 \mathrm{~N}\end{array}$ & $\begin{array}{l}\text { Textura granoblástica con granos. Fenocristales } \\
\text { de cuarzo xenomórfico y contactos saturados, } \\
\text { óxidos de hierro diseminados con forma de ban- } \\
\text { das, manchas y vetillas, sericita diseminada entre } \\
\text { granos de cuarzo, posibles minerales ferromag- } \\
\text { nesianos ( } 3 \% \text { ) hipidiomórficos alterados, arcillas } \\
\text { diseminadas. Minerales de alteración: óxidos de } \\
\text { hierro, arcilla Otros rasgos: vetillas, vesículas, } \\
\text { amígdalas. Cuarzo, sericita y óxidos de hierro dis- } \\
\text { persos en toda la muestra. }\end{array}$ & $\begin{array}{l}\text { No se puede deter- } \\
\text { minar }\end{array}$ & Grifo Alto \\
\hline $\mathrm{R} 27-7 / 48+000$ & $\begin{array}{c}447608,159 \mathrm{E} \\
1096624,297 \mathrm{~N}\end{array}$ & $\begin{array}{l}\text { Textura hipocristalina glomeroporfirítica seriada. } \\
\text { Matriz (41\%), intersertal compuesta por feldespa- } \\
\text { tos, piroxenos, opacos, arcillas y vidrio. Fenocris- } \\
\text { tales ( } 48 \%) \text {, plagioclasa ( } 30 \% \text { ) hipidiomórficos } \\
\text { con zonación, textura cribosa y fracturas rellenas } \\
\text { de calcita, opacos (4\%) cristales reabsorbidos, au- } \\
\text { gita }(8 \%) \text { hipidiomórficos alteradas por arcillas y } \\
\text { con fracturas rellenas de calcita, diópsido (6\%) hi- } \\
\text { pidiomórficos algunos con inclusiones de opacos } \\
\text { y plagioclasa y bordes de corona. Minerales de } \\
\text { alteración (10\%): calcita (8\%) alterando feldespa- } \\
\text { tos, sericita }(2 \%) \text { alterando plagioclasas, arcillas } \\
\text { alterando feldespatos, óxidos de hierro y epidota. } \\
\text { Minerales accesorios (<1\%): apatito. Otros ras- } \\
\text { gos: amígdalas (1\%), vetillas, autolito y cumulito. }\end{array}$ & $\begin{array}{c}\text { Andesita con augita y } \\
\text { diópsido }\end{array}$ & Grifo Alto \\
\hline
\end{tabular}


Cuadro 1 (continuación)

Composición petrográfica de muestras de roca tomadas en la zona de estudio

\begin{tabular}{|c|c|c|c|c|}
\hline $\begin{array}{c}\text { Código/ } \\
\text { Estacionamiento }\end{array}$ & $\begin{array}{l}\text { Coordenadas- } \\
\text { CRTM-2005 }\end{array}$ & Descripción microscópica & Clasificación & $\begin{array}{c}\text { Formación } \\
\text { geológica }\end{array}$ \\
\hline $\begin{array}{c}\text { M1-45+600/ } \\
45+600\end{array}$ & $\begin{array}{c}449185,331 \mathrm{E} \\
1097357,046 \mathrm{~N}\end{array}$ & $\begin{array}{l}\text { Textura holocristalina porfirítica. Matriz ( } 60 \%) \text {, pilo- } \\
\text { taxítica compuesta de microlitos de plagioclasa como } \\
\text { único mineral reconocible. Fenocristales ( } 25 \%) \text {, } \\
\text { plagioclasa ( } 25 \% \text { ) hipidiomórficos con zonación } \\
\text { continua. Minerales de alteración (14\%): calcita (sus- } \\
\text { tituyendo las plagioclasas en un } 15 \%) \text {, pirita ( } 5 \%) \text {, } \\
\text { hematita (3\%), clorita verde (4\%) y ceolita ( } 2 \%) \text {. Mi- } \\
\text { nerales accesorios (>1\%), apatito y zircón. }\end{array}$ & Andesita & Grifo Alto \\
\hline
\end{tabular}

ubicó dentro del croquis correspondiente (Fig. 3A). A una muestra relativamente sana de este sitio se le realizó una descripción mineralógica y petrográfica en detalle con la utilización del microscopio petrográfico con luz polarizante, para su posterior clasificación petrográfica (Cuadro 1).

\section{Muestreo general estacionamiento kilómetro $48+000$}

El primer muestreo en este sitio fue realizado en el mes de mayo del 2014 (inicio de la estación lluviosa). Se estableció una cuadrícula en donde se definieron 36 puntos de muestreo (Fig. 3B). Estos puntos de muestreo se distribuyeron a lo largo de toda el área, dando prioridad a las zonas que mostraban mayor indicio de alteración por DAR. En cada punto se removió un espesor superficial de suelo de unos $20 \mathrm{~cm}$ aproximadamente y se tomó una muestra de $2 \mathrm{~kg}$ del material. A cada muestra, se le realizó una descripción breve y se rotularon con un código específico. Se presenta la descripción petrográfica de cuatro muestras de roca de este sitio (en el cuadro 1).

\section{Muestreo en detalle estacionamiento kilómetro 48+000}

Durante la estación lluviosa (agosto de 2014), se muestreó en detalle una berma del talud ubicado en el estacionamiento del kilómetro
48+000. En esta ocasión solamente se obtuvieron muestras en el talud del LI y en la parte baja a nivel de la carretera. Se tomaron 22 muestras de suelo y roca, espaciadas entre sí una distancia de entre 4 a 6 m. También se realizó un escaneo lídar de los taludes de este sitio para poder ubicar con precisión las muestras del talud y mostrar su distribución. Además se obtuvieron los datos paramétricos de los taludes de este sitio incluyendo las pendientes (Fig. 4).

\section{Mediciones de $\mathbf{p H}$ de suelo y de aguas superfi- ciales in situ en el estacionamiento $48+000$}

Adicionalmente a la recolección de muestras de suelos, se tomaron muestras de material fino, las cuales se mezclaron en un vaso recto "beaker" de plástico con agua destilada, resultando una mezcla que se dejó reposar por 10 minutos, a la cual se realizó la medición del pH. En aquellos sitios en donde se encontrara agua estancada o saliendo de los drenajes de los taludes, también se hicieron mediciones de $\mathrm{pH}$ in situ. Se tomaron fotografías de los sitios en los cuales se realizaron las mediciones y de los resultados obtenidos mediante el pH-metro portátil.

\section{Mediciones de $\mathrm{pH}$ de suelos y rocas (pH en pasta) en el laboratorio}

Las mediciones de $\mathrm{pH}$ de suelos se realizaron en el Laboratorio de Química del LanammeUCR, 

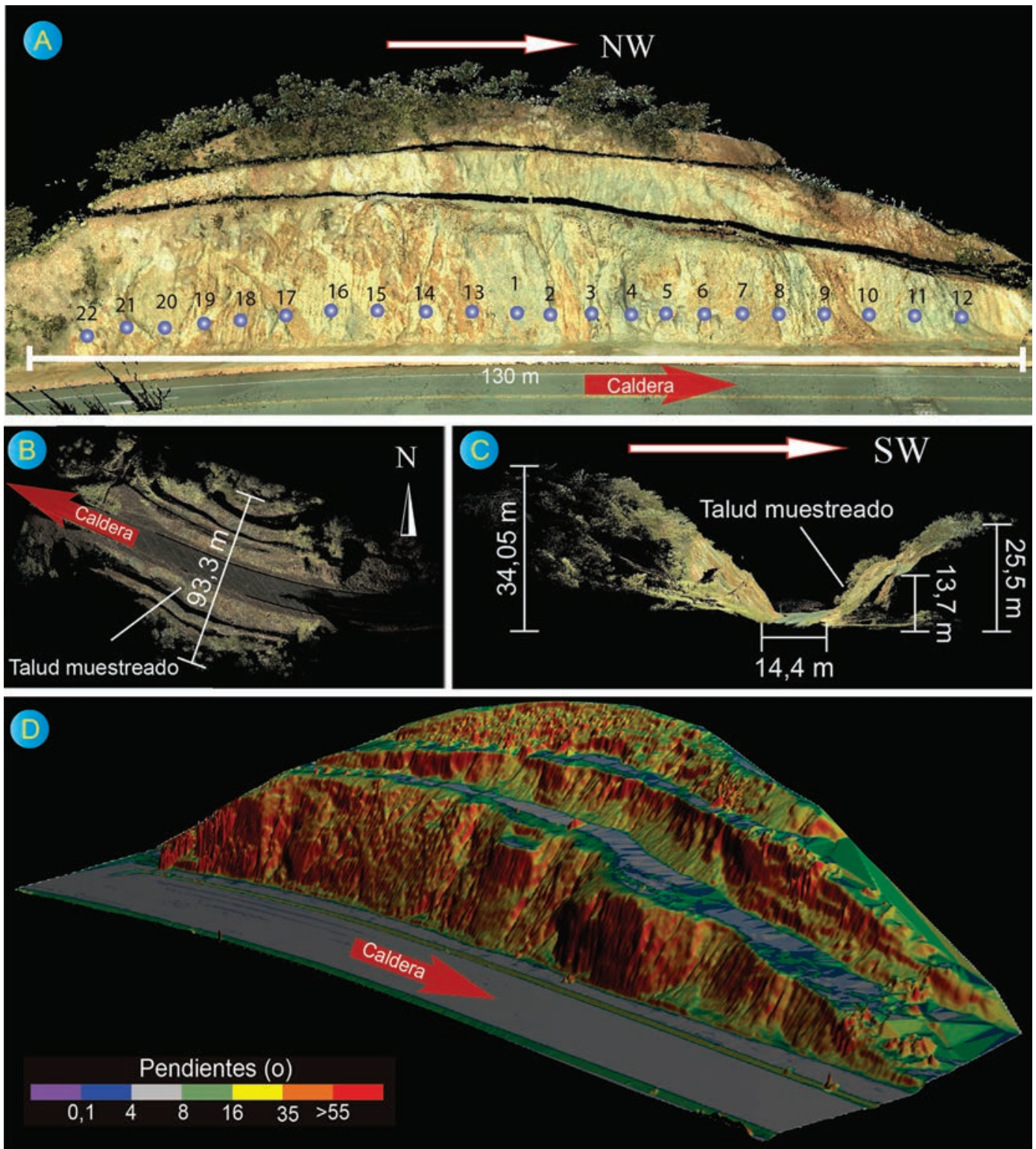

Fig. 4: Imágenes generadas a partir de un levantamiento topográfico que se realizó con el escáner lídar de LanammeUCR. El talud LD tiene una altura máxima $34,05 \mathrm{~m}$ y el LI de $25,5 \mathrm{~m}$. Ambos se extienden a lo largo de la carretera aproximadamente $130 \mathrm{~m}$. A) Vista de frente del talud muestreado presentando la ubicación de cada una de las muestras. B) Vista de planta del talud muestreado. C) Vista de perfil del talud muestreado. D) Vista oblicua del talud muestreado con las pendientes de cada una de las bermas.

mientras que los análisis de $\mathrm{pH}$ de rocas se realizaron en el Laboratorio de Geoquímica de la Escuela Centroamericana de Geología (ECG, UCR). En ambos casos, se siguió la metodología propuesta por Sobek et al. (1978) para determinar el $\mathrm{pH}$ en una pasta para suelos y rocas usada en minería y que es derivada de pruebas que se hacen en mediciones agrícolas (USEPA, 1994). El pH en pasta proporciona una indicación de la generación neta de ácido asociada con una muestra, ya 
que el $\mathrm{pH}$ es un control fundamental, tanto en los índices de reacción primaria, como en la solubilidad del mineral (MEM-PERÚ, 2015). En general, estas mediciones consisten en tomar una cantidad determinada de material fino en el campo, luego disgregar o moler el material y tamizar con malla Nº10 (apertura $2 \mathrm{~mm}$ ), y descartar la fracción gruesa. Se preparan las disoluciones patrón de $\mathrm{pH}$ 4,0 y 7,0 y se calibra el $\mathrm{pH}$-metro. Posteriormente se combina y se mezcla muy bien una pasta 1:1 de agua: muestra, es decir, a $20 \mathrm{~mL}$ de agua destilada se le agregan $20 \mathrm{~g}$ del material, se deja reposar por 10 minutos y se inserta el $\mathrm{pH}$-metro moviendo suavemente la solución supernatante, finalmente se mide electroquímicamente el pH. Este proceso se hizo por triplicado y se tomó el promedio de las tres mediciones de cada muestra analizada.

A cada muestra de roca seca, previamente pulverizada y tamizada en una malla de $200 \mu \mathrm{m}$, se le agregaron con una probeta 20,0 $\pm 0,5 \mathrm{~mL}$ de agua ultra pura con una resistividad de 18,2 M $/$ / cm recién obtenida del purificador. Las muestras se ponen en agitación en un agitador con una pastilla magnética por 10 minutos a temperatura ambiente. Mientras tanto, se toman las medidas necesarias para evitar la contaminación cruzada entre las muestras o los patrones. Se introduce el electrodo para hacer la medición. Se espera a que se estabilice la medida. Si los resultados obtenidos de este experimento, dan un $\mathrm{pH}<5,5$ esto indica que a partir de las rocas o suelos analizados se está generando una concentración de iones hidronio tal que ocasiona el drenaje ácido de rocas. Esto se puede explicar por la mayor presencia de sulfuros y poca o nula presencia de carbonatos en la composición de la muestra. Cuando este tipo de rocas o suelos ricos en sulfuros, entra en contacto con el oxígeno en medio acuoso, sumado a la acción catalizadora de bacterias ferro-oxidantes, se genera drenaje ácido de roca. Los valores entre 5,5 y 7 se consideran como de acidez baja. Mientras que si los resultados obtenidos de las mediciones $\mathrm{pH}$ son mayores a 7, esto indica que las muestras analizadas van a generar drenajes neutros o alcalinos y se explican por una poca o nula presencia de minerales de sulfuros y una mayor presencia de minerales carbonatados (MEM-PERÚ, 2015).

\section{Mediciones de pH y química de aguas ex situ}

Se realizaron mediciones de $\mathrm{pH}$ del agua en algunos drenajes que descargan el líquido de los taludes de la RN-27, así como en sitios donde se encontrara agua estancada. Estas mediciones se realizaron en conjunto con el Laboratorio de Geoquímica de la ECG-UCR. Para ciertas muestras de agua estancada, se realizaron otros análisis más detallados en el laboratorio (concentración en $\mathrm{mg} / \mathrm{L}$ de fluoruros, cloruros, nitritos, nitratos, fosfatos, sulfuros, litio, sodio, amonio, potasio, calcio y magnesio, entre otros). La incertidumbre de cada medición es 0,01 unidades de $\mathrm{pH}$. Se tomaron cerca de $20 \mathrm{~g}$ de suelo con una balanza analítica.

\section{DRENAJE ÁCIDO DE ROCAS (DAR)}

El término “drenaje ácido de rocas” hace referencia a la acidificación de las aguas naturales como consecuencia de la descomposición por oxidación de rocas que contienen minerales metálicos ricos en azufre o sulfuros (p.ej., pirita, arsenopirita, marcasita, calcopirita y esfalerita, entre otros). Estos tienden a oxidarse al estar expuestos a los agentes naturales como el agua y el aire. Durante el proceso de oxidación del mineral, se libera azufre, el cual se combina con el agua y el oxígeno del aire para formar ácido sulfúrico (Fig. 5). Al mismo tiempo, se liberan metales, los cuales pueden incorporarse al agua (USEPA, 1994; Grandia et al., 2009 \& Dold, 2010). Esto genera aguas acidas las cuales afectan las rocas y estructuras civiles, estas aguas son clasificadas según su acidez (USEPA, 1978, 1994 y Ruiz, 2004) tal como se muestra en el cuadro 2.

\section{Procesos de generación de ácido sulfúrico asociado en la $\mathrm{RN}-27$}

La generación de iones hidronio a partir de las rocas es una consecuencia de la oxidación de los minerales sulfurosos que contiene, en un proceso que consiste en varias reacciones con cinéticas distintas que dependen de la identidad del 

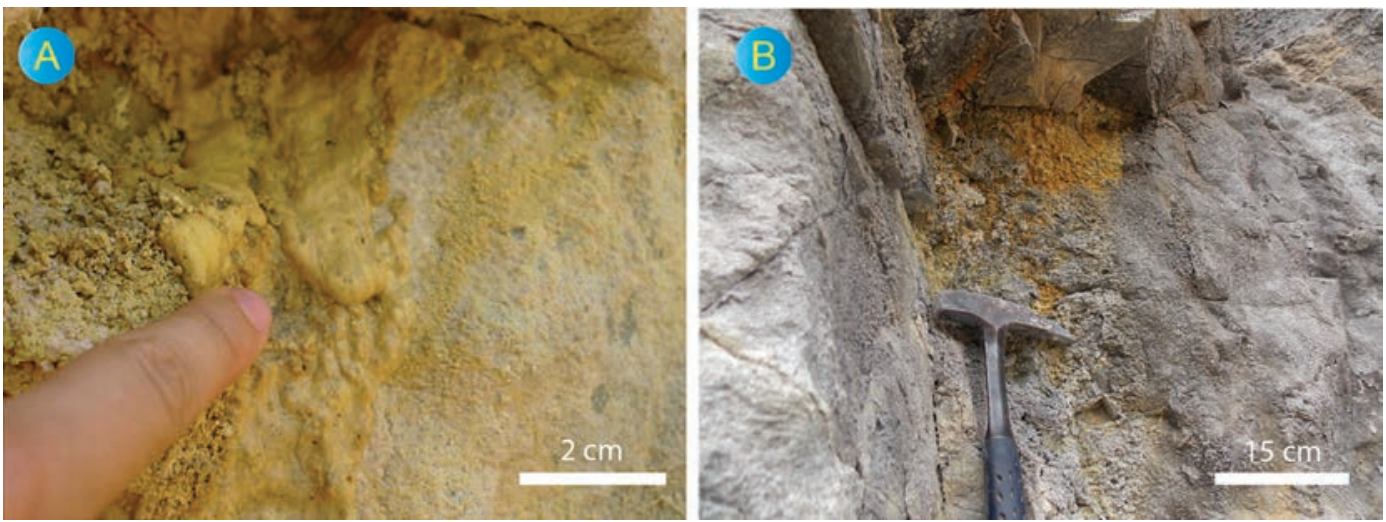

Fig. 5: A) Afloramiento en estacionamiento $(46+300)$. Se muestra la presencia de azufre con una textura fluidal en primer plano, pero también en forma de seudoesferas o nódulos en la parte superior izquierda. B) Azufre en nódulos en afloramiento en estacionamiento $(48+000)$. Este azufre posiblemente sea el resultado de la oxidación de pirita, que también fue identificada en las rocas de estos sitios.

sulfuro. Por ejemplo, la marcasita y la pirita framboidal tienen una tasa de oxidación más rápida que la de la pirita cristalina, la cual se oxida lentamente (USEPA, 1994 \& Grandia et al., 2009). Debido a que hasta el momento solamente se ha podido identificar pirita $\left(\mathrm{FeS}_{2}\right)$ en forma cúbica en la zona estudiada de la $\mathrm{RN}-27$, en este trabajo nos limitaremos a explicar en detalle la oxidación de este mineral según la información presentada por USEPA (1994).

$2 \mathrm{FeS}_{2(\mathrm{~s})}+2 \mathrm{H}_{2} \mathrm{O}_{\text {(l) }}+7 \mathrm{O}_{2(\mathrm{~g})} \rightarrow 4 \mathrm{H}^{+}{ }_{\text {(ac) }}+4 \mathrm{SO}_{4}^{2-}{ }_{\text {(ac) }}+2 \mathrm{Fe}^{2+}{ }_{\text {(а) }}$

En este paso, el ion sulfuro es oxidado en medio acuoso para formar aniones sulfato e iones hidronio, que son los productos de disociación del ácido sulfúrico en disolución acuosa. El catión hidratado $\mathrm{Fe}^{2+}{ }_{\text {(ас) }}$ queda libre en disolución para seguir reaccionando. La oxidación del ion ferroso ocurre más despacio a valores de pH bajos.

$4 \mathrm{Fe}^{2+}{ }_{\text {(ас) }}+\mathrm{O}_{2(\mathrm{~g})}+4 \mathrm{H}^{+}{ }_{\text {(ас) }} \rightarrow 4 \mathrm{Fe}^{3+}{ }_{\text {(ас) }}+2 \mathrm{H}_{2} \mathrm{O}_{\text {(1) }}$

A niveles de $\mathrm{pH}$ entre 3,5 y 4,5 , la oxidación del hierro es catalizada por la bacteria Metallogenium filamentous bacterium. Por debajo de $\mathrm{pH}=3,5$ la misma reacción es realizada por la bacteria Thiobacillus ferroxidans. Si el ion férrico se forma en contacto con la pirita, la siguiente reacción puede ocurrir, disolviendo la pirita.
$2 \mathrm{FeS}_{2(\mathrm{~s})}+14 \mathrm{Fe}^{3+}{ }_{\text {(ac) }}+8 \mathrm{H}_{2} \mathrm{O}_{(\mathrm{f})} \rightarrow 15 \mathrm{Fe}^{2+}{ }_{\text {(ac) }}+2 \mathrm{SO}_{4}^{2-}{ }_{\text {(ac) }}+16 \mathrm{H}^{+}{ }_{\text {(ac) }}$

Esta reacción genera más iones hidronio. La disolución de pirita por hierro férrico $\left(\mathrm{Fe}^{3+}\right)$, en conjunto con la oxidación del ion ferroso constituye un ciclo de disolución de pirita. El hierro férrico precipita como hierro hidratado, como se indica en la siguiente reacción.

$$
\mathrm{Fe}^{3+}{ }_{\text {(ac) }}+3 \mathrm{H}_{2} \mathrm{O}_{\text {(l) }} \longleftrightarrow \mathrm{Fe}(\mathrm{OH})_{3(\mathrm{~s})}+3 \mathrm{H}^{+}{ }_{\text {(ac) }}
$$

$\mathrm{El} \mathrm{Fe}(\mathrm{OH})_{3}$ precipita y es identificable como un depósito amorfo de color amarillo, anaranjado o rojo en cauces o donde el agua se estanque, producto al cual se le conoce coloquialmente con el nombre de yellow boy.

$\mathrm{El} \mathrm{Fe}{ }^{3+}$ puede ayudar a oxidar otros minerales metálicos presentes en las rocas, tales como la galena y la arsenopirita. Al lixiviarse los componente de este y de otros minerales, se podrían liberar elementos tóxicos como el plomo y el arsénico, que son muy contaminantes para el ambiente.

\section{Características típicas del DAR}

El DAR es difícil de predecir y prevenir, aunque existen técnicas para determinar su potencial de generación de una zona. Puede permanecer latente por muchos años, y cuando inicia, es muy 
Cuadro 2

Clasificación de aguas según su acidez (USEPA, 1978, 1994; Ruiz, 2004)

\begin{tabular}{cc}
\hline Clasificación & $\mathrm{pH}$ \\
\hline Altamente acidas & $1,5-4,5$ \\
Blandas acidas & $3,5-5,5$ \\
Blandas a ligeramente & $5,0-7,0$ \\
acidas & $7,0-8,5$ \\
Duras a neutras alcalinas & $7,5-11,0$ \\
Blandas a alcalinas & $6,0-9,0$ \\
Muy salina &
\end{tabular}

difícil y extremadamente caro detenerlo (en algunos casos hasta US\$ 500000 por hectárea) y puede aumentar paulatinamente. Muchas veces no se puede corregir y puede originar contaminación por muchos años (USEPA, 1994).

\section{Síntomas de un sitio que está siendo afectado por DAR}

Algunos de los síntomas del proceso de DAR que se pueden observar en un sitio afectado por este fenómeno según USEPA (1994), y que están ocurriendo en los taludes de la RN-27, son los precipitados de hierro (III) (yellow boy) en las zonas de encharcamiento (aguas de bajo $\mathrm{pH}$ ), como en las cunetas; la presencia de sulfatos como el yeso, también es común (en mayo del 2014 se encontraron cristales milimétricos -centimétricos de este mineral); así como la oxidación de sulfuros, puesen varios sitios se observaron rocas ricas en pirita, cerca de ellas se encontró azufre y en varios sitios es frecuente un fuerte olor azufroso.

\section{RESULTADOS Y DISCUSIÓN SOBRE LA DETERMINACIÓN DE LA PRESENCIA DE DAR EN LA RN-27}

\section{Geología y petrografía de los sitios muestrea- dos y analizados}

En general, el área de estudio presenta tres unidades geológicas: 1.) Formación Grifo Alto,
2.) Unidad de epiclastos varios donde predominan materiales de tipo Debris Avalanche, junto con brechas volcánicas y hasta aluviones interdigitados, y 3.) Formación Tiribí, que corresponde con ignimbritas con diferentes facies de enfriamiento. Finalmente hay algunos aluviones ubicados en barras de punto a lo largo del río Grande de Tárcoles, tal y como se observa en el mapa geológico propuesto para la zona de estudio (Fig. 6).

Las rocas analizadas en los estacionamientos 45+600 y 48+000, corresponden con materiales de la Formación Grifo Alto (Denyer \& Arias, 1991; Porras et al., 2012). Esta formación está compuesta de rocas volcánicas, del Plioceno, expuestas en los montes del Aguacate, predominantemente brechas volcánicas de diversos tipos, constituidas por fragmentos de pómez y de lavas, y depósitos aluvionales, además de coladas subordinadas. También se observa en algunos sectores cuerpos hipoabisales (diques/sills) con profusa alteración propilítica, lo que sumado a la fuerte alteración hidrotermal de la zona, evidencia la presencia de un antiguo estratovolcán (Porras et al., 2012).

Específicamente en los sitios analizados afloran coladas de lavas masivas, afectadas por fallas tectónicas, fracturas, alteración hidrotermal y como se demuestra en este trabajo, DAR (Fig. 7). Debido a esto y por los procesos normales de meteorización en una zona tropical, estas lavas presentan diferentes grados del alteración, que van desde poca alteración, hasta la degradación completa de los minerales originales constituyentes de las rocas. En varios sitios donde hay presencia de alteración hidrotermal, las rocas pueden presentar arcillitización intensa o en otros casos (los menos frecuentes) han sufrido procesos de silicificación, tornándose más duras y resistentes a la meteorización química y erosión. Sin embargo, estos sitos no son de gran extensión. Los que sí predominan son los sitios con gran degradación de los materiales, especialmente en el estacionamiento del

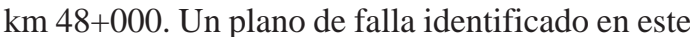
sitio, tiene un rumbo de $\mathrm{N} 24^{\circ} \mathrm{E}$, con un buzamiento de $66^{\circ}$ hacia el NW.

Se realizaron análisis petrográficos a cinco diferentes muestras con diferentes grados de alteración en los estacionamientos con kilometraje $45+600$ y 48+000. Cuatro de ellas se identificaron como andesitas, algunas de estas 

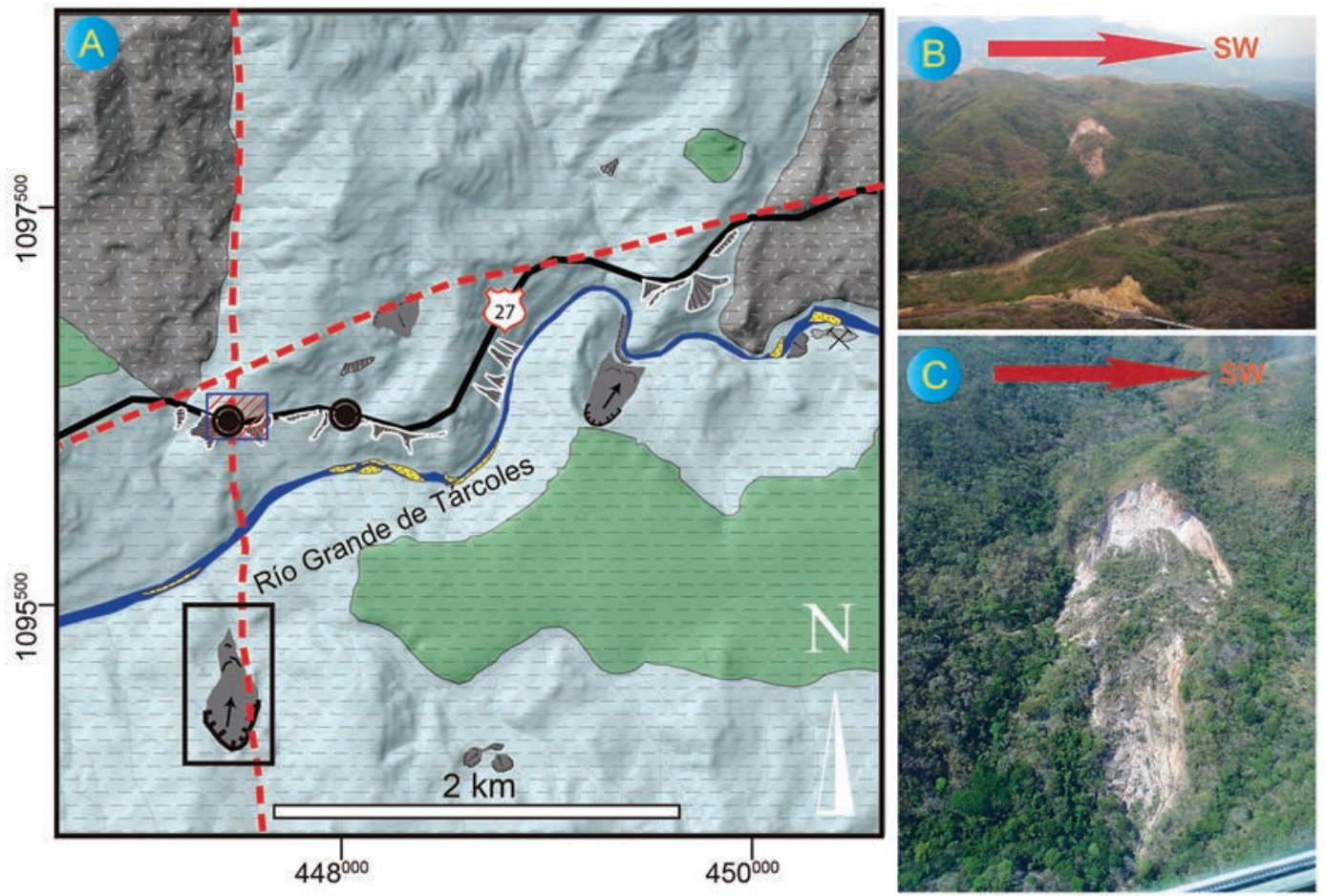

\section{UNIDADES GEOLÓGICAS}

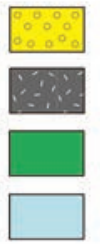

Aluviones recientes

Unidad de epiclastos varios

Formación Tiribí

Formación Grifo Alto



Falla inferida

Deslizamiento activo

DA DAR confirmado

Conos de talus escombreras



Sistema de coordenadas: CRTM05

Fuente: Curvas 1: 25000 Proyecto Terra

Fig. 6. A.) Mapa geológico del área de estudio. B.) Fotografía aérea oblicua donde se observa en la parte inferior la RN-27, específicamente el talud muestreado en el estacionamiento del km 48+000, en la parte media, se observa el río Grande de Tárcoles y más atrás un deslizamiento activo de tamaño considerable que podría afectar un poliducto ubicado sobre el cauce del río. C.) Detalle de deslizamiento en la margen izquierda del río Grande de Tárcoles, se notan materiales muy meteorizados y similares a los observados en los taludes de la RN-27. Fotografías cortesía de Gerardo Soto.

con minerales secundarios (calcita, clorita verde, ceolita, hematita y pirita) producto de la misma afectación de procesos hidrotermales. La muestra restante no se pudo clasificar debido a su alto grado de alteración (Cuadro 1).

\section{Resultados de las mediciones de $\mathrm{pH}$ en pasta km 45+600}

Los resultados del muestreo realizado en este sitio provienen de 37 muestras de rocas analizadas en el Laboratorio de Geoquímica de la ECG. Estos se resumen en el cuadro 3 y se muestra en la figura 8A.

Según los resultados obtenidos, las rocas de este sitio, a pesar de tener una coloración rojiza en su parte externa, no están generando DAR. El valor de pH más bajo obtenido en las mediciones del laboratorio fue de 7,29, mientras que el valor promedio de $\mathrm{pH}$ fue de 7,98. Por lo tanto, se puede considerar que los materiales rocosos, tanto del talud del LD como del LI están generando drenajes alcalinos. 


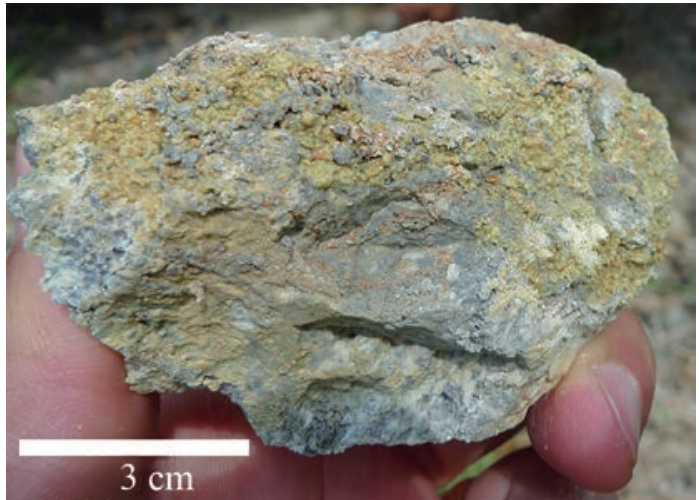

Fig. 7: Muestras de lava andesítica de la Formación Grifo Alto, con alto grado de alteración hidrotermal y presencia de nódulos de sulfuros, ubicada en el estacionamiento 48+000.

Los siguientes aspectos se consideran para explicar el carácter alcalino de las rocas de este sitio. A pesar de que la petrografía de la muestra analizada indica la presencia de minerales que podrían corresponder con sulfuros y que en algunas muestras de mano se observaron cristales de pirita, el porcentaje en que este mineral está presente, no parece ser suficiente para que al estar en contacto con el oxígeno y agua se genere ácido sulfúrico. Otra posibilidad para explicar el carácter alcalino de las rocas de este sitio, es la presencia de minerales de alteración de tipo calcáreo (calcita) que están sustituyendo las plagioclasas originales de las rocas. La calcita está actuando como neutralizador y aunque existan sulfuros en las rocas, el carbonato de calcio controla la posibilidad de generar ácido sulfúrico. Posiblemente la pátina rojiza que presentan en la parte externa de estas rocas, sea por deposición de óxidos por los fluidos que corren sobre ellas.

Se considera que los problemas de estabilidad del macizo rocoso que se están dando en este sitio específico, no están directamente relacionados con la inconsistencia de los materiales debido a DAR. Otras variables como las pendientes tan pronunciadas (en algunos casos verticales), las rocas densamente fracturas, así como la gran cantidad de agua que atraviesa y baja por ellas, son posiblemente las principales razones que influyen en la generación de problemas de estabilidad y que se traducen en deslizamientos de tipo caída de bloques.

\section{Resultados de mediciones muestreo general del talud km 48+000}

Los resultados del primer muestreo realizado en este sitio provienen de 36 muestras de suelo que fueron analizadas en el Laboratorio de Química del LanammeUCR. En el cuadro 4 se resumen los resultados estadísticos más importantes del experimento.

Todas las muestras de suelo analizadas en este sitio, presentan una acidez $<5,35$, por lo que según la clasificación de USEPA (1994), se podrían agrupar entre altamente ácidas y blandas ácidas. Al realizar una comparación de la acidez de los suelos de este sitio con otros líquidos o compuestos, se nota que estos suelos presentan valores menores que la lluvia ácida y la mayoría presentan una acidez similar a la del ácido gástrico $(2,0)$ o ácido de batería $(<1,0)$.

Al mostrar la distribución de acidez de los suelos analizados en este sitio, se observa que las muestras con los valores de pH más bajos están ubicadas en la zona central del talud, tanto del lado izquierdo como del lado derecho. Las muestras ubicadas en sector NE y alejándose del núcleo del talud presentan los valores más altos de $\mathrm{pH}$, sin embargo todas presentan valores por debajo del pH neutro (Fig. 8B). En la parte central del talud se encontraron fracturas y varios planos de falla. Con base en los resultados de $\mathrm{pH}$ obtenidos y su distribución cerca de estas estructuras, se consideró que la acidez de los materiales en el talud podría estar directamente asociada con la ubicación de esta zona de falla.

Sin embargo como se describe más adelante, el muestreo en detalle del talud mostró que en realidad el talud en la parte inferior se comporta de forma muy homogénea y que los cambios de $\mathrm{pH}$ no son significativos excepto en los bordes del talud.

\section{Resultados de muestreo en detalle, talud estacionamiento $\mathrm{km} \mathbf{4 8 + 0 0 0}$}

Los resultados del muestreo en detalle realizado en este sitio provienen de 22 muestras analizadas y distribuidas a lo largo de la parte inferior 
Cuadro 3

Resultados de muestras analizadas en mayo del 2014 de taludes en estacionamiento km 45+600 de la RN-27

\begin{tabular}{cc}
\hline Muestras analizadas & 37 \\
\hline $\begin{array}{c}\text { Temperatura promedio del agua durante } \\
\text { mediciones }\end{array}$ & $24,0^{\circ} \mathrm{C}$ \\
Valor más bajo de $\mathrm{pH}$ & 7,29 \\
Valor más alto de pH & 9,77 \\
Valor promedio & 7,98 \\
\hline
\end{tabular}

del talud LI (Fig. 4). Los resultados analíticos se muestran gráficamente en la figura 9 .

Según la clasificación de $\mathrm{pH}$ de USEPA (1994), este sitio corresponde con una alta acidez, los niveles en algunos casos son muy cercanos a los que se pueden obtener por ácido de batería. El borde izquierdo de la zona de muestreo (primeros 6 metros), presenta el valor más alto (pH 3,31), pero este valor es anómalo comparado con el resto, mientras que los valores más bajos de $\mathrm{pH}$ 1,52 están ubicados en la parte central entre los 66 y $78 \mathrm{~m}$.

Se considera que como el muestreo en detalle se realizó en el mes de agosto, cuando la estación lluviosa ya estaba instalada, la lixiviación y movimiento de ácido sulfúrico entre las rocas era mayor que cuando se realizó el muestreo general del sitio en el mes de mayo, cuando las lluvias apenas iniciaban y la movilidad de los fluidos lixiviados no era tan alta.

\section{Resultados de análisis de pH y química de aguas en laboratorio}

Se procedió a tomar muestras de agua en los estacionamientos $\mathrm{km} 21+400$ y en el $48+000$ para establecer principalmente su $\mathrm{pH}$, además de otros parámetros como conductividad eléctrica, oxígeno disuelto, potencial de óxido reducción y temperatura. La muestra del kilómetro $21+400$ se tomó en un sitio donde no hay evidencias de alteración hidrotermal o DAR, así se tiene una mejor
Cuadro 4

Resultados de muestras analizadas en mayodel 2014 de, talud en estacionamiento km 48+000 de la RN-27

\begin{tabular}{cc}
\hline Muestras analizadas & 36 \\
\hline $\begin{array}{c}\text { Temperatura promedio del agua durante } \\
\text { mediciones }\end{array}$ & $24,2^{\circ} \mathrm{C}$ \\
Valor más bajo de $\mathrm{pH}$ & 1,32 \\
Valor más alto de $\mathrm{pH}$ & 5,35 \\
Valor promedio & 2,8 \\
\hline
\end{tabular}

comparación de la acidez y la química de un sitio afectado por DAR y uno donde no se da este proceso (Cuadro 5). A continuación se presentan las observaciones sobre estos resultados.

Los resultados muestran la disparidad entre ambas muestras de agua. La muestra del estacionamiento km 48+000 es más ácida, más cálida, más anóxica, con mayor conductividad eléctrica y es más concentrada en todos los iones mayores, excepto para el potasio; su bajo $\mathrm{pH}$ medido es debido a una alta concentración de iones hidronio (10-1,53 $\mathrm{M} \approx 0,03 \mathrm{~mol} / \mathrm{L})$ que implica una reducción en la presencia iones carbonato libres y quizá también la de los iones hidrógeno carbonato, por lo que el principal anión es el sulfato (40 $\mathrm{g} / \mathrm{L}$ ), consistente con la oxidación del sulfuro de la pirita de las rocas. Los cationes más abundantes son el $\mathrm{Mg}^{2+}$ y el $\mathrm{Ca}^{2+}$, que le dan mayor dureza a esas aguas y son más susceptibles de tener índices de saturación altos para los sulfatos de magnesio y calcio, los cuales pueden precipitar si aumenta el $\mathrm{pH}$, baja la temperatura, se diluye la muestra o si ocurre una combinación de los tres. No se hicieron determinaciones de la concentración de hierro en el agua, pero el color de la muestra (rojo intenso) y la pátina que recubre los alrededores, delata su presencia (aunque también podría atribuirse a la presencia de bacterias), mientras que la reducida concentración de oxígeno disuelto hace pensar que la especie predominante sea el $\left[\mathrm{Fe}\left(\mathrm{H}_{2} \mathrm{O}\right) 6\right]^{2+}$ o algún otro complejo análogo de hierro-II, sin descartar la presencia de hierro-III en disolución favorecida por el bajo nivel de $\mathrm{pH}$. 

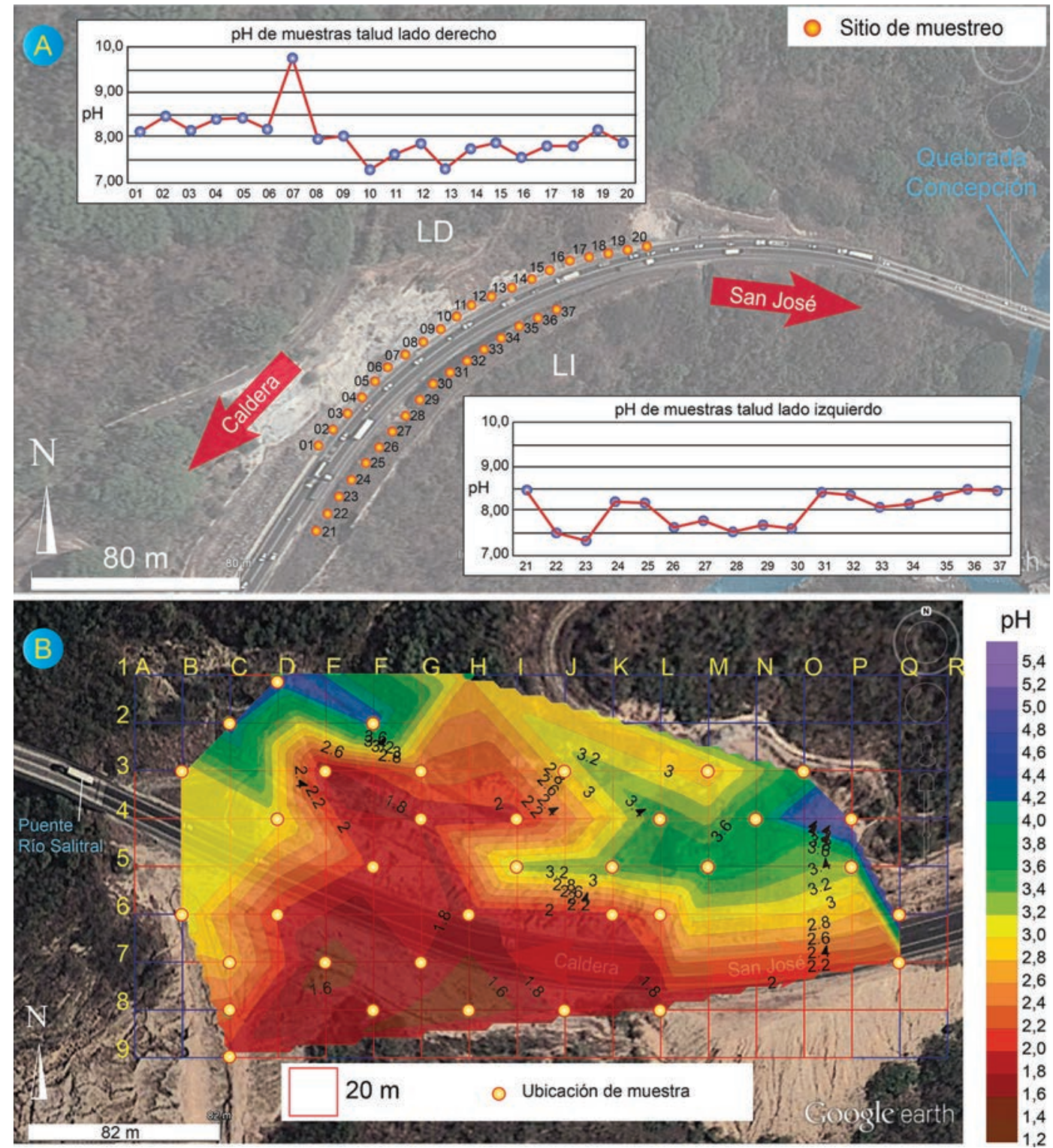

Fig. 8: A) Resultados de la determinación de $\mathrm{pH}$ en pasta realizados a las rocas ubicadas en los taludes rocosos del estacionamiento 45+600. Como se observa, todas las muestras presentan valores de pH superiores a 7. B) Resultados de muestreo general de suelos en talud de estacionamiento 48+000, la distribución de la curvas se realizó con una interpolación de tipo triangulación lineal, con el fin de no generar interpolación en las zonas donde no existen datos.

En contraste, la muestra del estacionamiento


roca tenía un color grisáceo, es ligeramente básica, fría, incolora, diluida y con condiciones oxidantes. Sin otra información adicional, podría suponerse que tiene poca o ninguna influencia de DAR en comparación con la muestra de agua del estacionamiento km 48+000. 


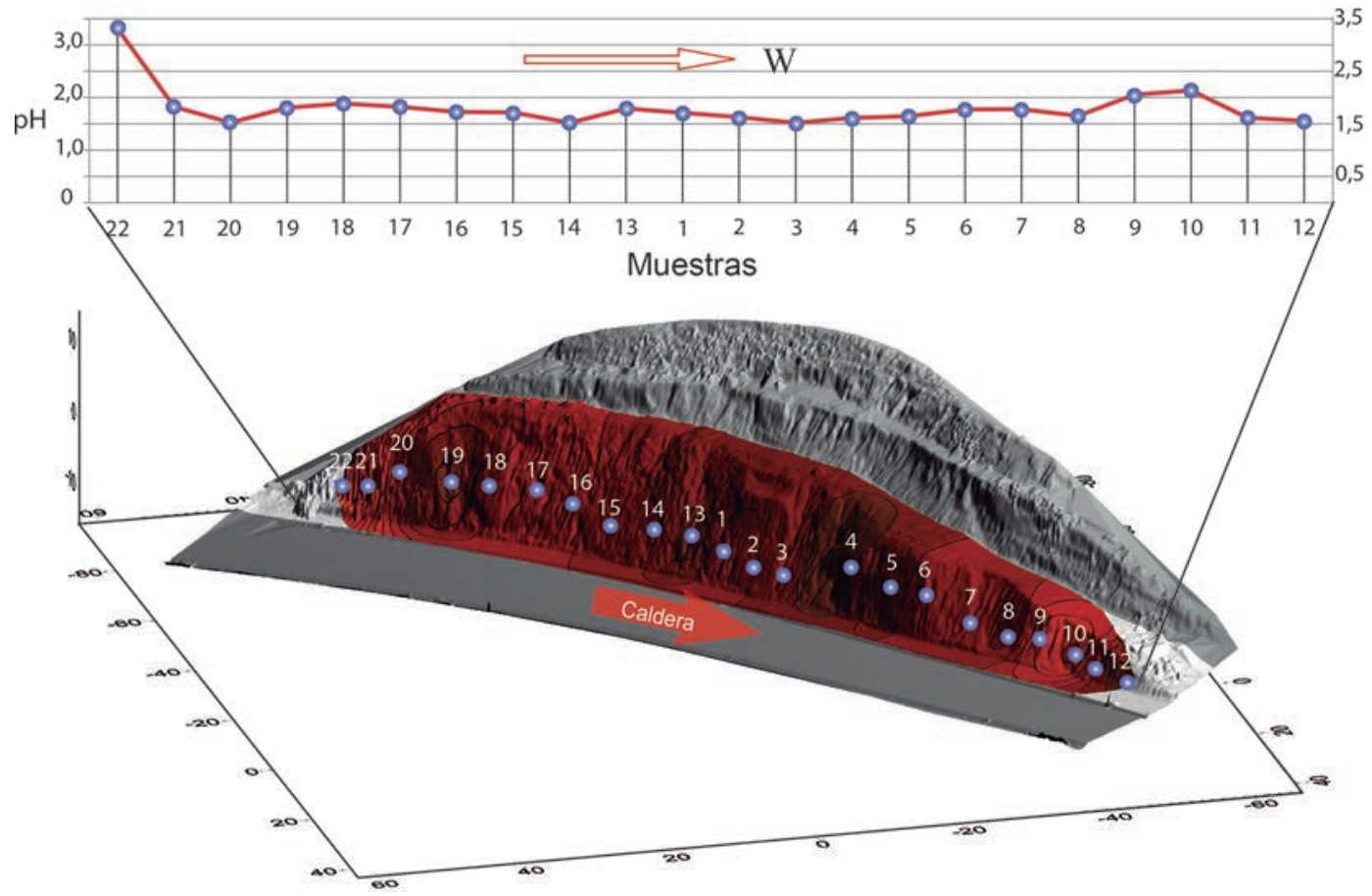

Fig. 9: Distribución de pH en los suelos y rocas tomadas de la parte inferior del LI del talud en el estacionamiento del kilómetro 48+000. Nótese cómo la variación es muy poca y casi todas las muestras presentan valores de pH inferiores a 2.

\section{Medición de $\mathbf{p H}$ in situ de aguas y problemas identificados atribuidos a DAR}

Se presentan los resultados de mediciones de $\mathrm{pH}$ de aguas superficiales en varios sitios de la $\mathrm{RN}-$ 27 y problemas observados en varios taludes que se pueden atribuir a efectos del DAR. Es recomendable realizar pruebas de $\mathrm{pH}$ en pasta en estos taludes para comprobar y determinar la intensidad del drenaje que se está dando en estos puntos.

\section{Estacionamiento km 38+700}

En este sitio, en el talud del LD hay presencia de pátinas de óxidos de hierro y manganeso en el concreto lanzado y las cunetas. Estas estructuras de drenaje se observan muy desgastadas en la parte central por donde discurre el agua y los agregados líticos están completamente expuestos, lo que evidencia la pérdida del componente calcáreo. El concreto lanzado de este sitio presenta lixiviación intensa que ha afectado severamente sus propiedades físicas, hasta el punto de que se desgrana completamente. En la parte inferior del talud, el concreto lanzado está agrietado y permite la salida de agua, que está lavando el material más fino y suelos del talud, lo cual ha ocasionado inestabilidad al talud y hace que el concreto se esté resquebrajando aún más.

Hay puntos en este talud donde las pendientes son muy fuertes con ángulos casi verticales y hasta con pendientes negativas. En las zonas donde el concreto ha colapsado, hay material en voladizo y el acero de las mallas electrosoldadas está expuesto. El acero se presenta con oxidación y corrosión intensa.

Una medición del $\mathrm{pH}$ in situ de las aguas que fluyen en la parte inferior del talud, dio como resultado 5,5 (ligeramente ácido, cercano al límite superior de la lluvia considerada ácida). Se considera que las características tan desfavorables presentes en el concreto lanzado y el acero de la malla electrosoldada de este talud, se debe a afectación por DAR. Sin embargo, se recomienda realizar mediciones de $\mathrm{pH}$ en pasta de los materiales originales del talud para comprobar esta situación. 
Cuadro 5

Resultados geoquímicos del análisis de muestras de agua en la RN-27

\begin{tabular}{|c|c|c|c|}
\hline $\mathrm{N}^{\circ} \mathrm{LGQ}$ & & LGQ141020-01 & LGQ141020-02 \\
\hline Código original & & Q01 & R03 \\
\hline Fecha de toma & $(\mathrm{dd} / \mathrm{mm} / \mathrm{aa})$ & 20/10/2014 & 20/10/2014 \\
\hline Estacionamiento & & $\mathrm{km} \mathrm{21+400}$ & $\mathrm{km} \mathrm{48+000}$ \\
\hline Temperatura & ${ }^{\circ} \mathrm{C}$ & $29,7 \pm 0,1$ & $38,2 \pm 0,1$ \\
\hline $\mathrm{pH}$ & $\mathrm{pH}$ & $7,78 \pm 0,01$ & $1,53 \pm 0,01$ \\
\hline Cond. & $\mu \mathrm{S} / \mathrm{cm}$ & $287,5 \pm 0,1$ & $17485 \pm 1$ \\
\hline OD & $\mathrm{mg} / \mathrm{L}$ & $7,0 \pm 0,1$ & $0,71 \pm 0,1$ \\
\hline ORP & $\mathrm{mV}$ & $70 \pm 10$ & $428 \pm 20$ \\
\hline Litio $\left(\mathrm{Li}^{+}\right)$ & $\mathrm{mg} / \mathrm{L}$ & $<0,009$ & $<0,9$ \\
\hline Sodio $\left(\mathrm{Na}^{+}\right)$ & $\mathrm{mg} / \mathrm{L}$ & $17,4 \pm 0,4$ & $32 \pm 4$ \\
\hline Amonio $\left(\mathrm{NH}_{4}^{+}\right)$ & $\mathrm{mg} / \mathrm{L}$ & $<0,04$ & $12 \pm 3$ \\
\hline Potasio $\left(\mathrm{K}^{+}\right)$ & $\mathrm{mg} / \mathrm{L}$ & $1,13 \pm 0,06$ & $1,8 \pm 0,6$ \\
\hline Calcio $\left(\mathrm{Ca}^{2+}\right)$ & $\mathrm{mg} / \mathrm{L}$ & $52,3 \pm 0,8$ & $672 \pm 6$ \\
\hline Magnesio $\left(\mathrm{Mg}^{2+}\right)$ & $\mathrm{mg} / \mathrm{L}$ & $1,20 \pm 0,04$ & $590 \pm 3$ \\
\hline Fluoruro $\left(\mathrm{F}^{-}\right)$ & $\mathrm{mg} / \mathrm{L}$ & $0,22 \pm 0,09$ & $71 \pm 8$ \\
\hline Cloruro $\left(\mathrm{Cl}^{-}\right)$ & $\mathrm{mg} / \mathrm{L}$ & $1,02 \pm 0,05$ & $8 \pm 2$ \\
\hline Nitrito $\left(\mathrm{NO}_{2}^{-}\right)$ & $\mathrm{mg} / \mathrm{L}$ & $<0,6$ & $<57$ \\
\hline Nitrato $\left(\mathrm{NO}_{3}^{-}\right)$ & $\mathrm{mg} / \mathrm{L}$ & $<0,6$ & $<66$ \\
\hline Fosfato $\left(\mathrm{PO}_{4}^{3-}\right)$ & $\mathrm{mg} / \mathrm{L}$ & $<2$ & $<190$ \\
\hline Sulfato $\left(\mathrm{SO}_{4}^{2-}\right)$ & $\mathrm{mg} / \mathrm{L}$ & $16,3 \pm 0,5$ & $(40 \pm 1) \times 1000$ \\
\hline Dureza cálcica & mg/L CaCO3 & 131 & 1678 \\
\hline Dureza magnésica & mg/L CaCO3 & 5 & 2430 \\
\hline Dureza total & mg/L CaCO3 & 136 & 4108 \\
\hline Alcalinidad $\mathrm{OH} / \mathrm{CO}_{3}$ & mg/L CaCO3 & $<1$ & no se midió \\
\hline Alcalinidad $\mathrm{HCO}_{3}$ & mg/L CaCO3 & 268 & no se midió \\
\hline Alcalinidad total & mg/L CaCO3 & 268 & no se midió \\
\hline Carbonatos $\left(\mathrm{CO}_{3}^{2-}\right)$ & $\mathrm{mg} / \mathrm{L}$ & $<1$ & no se midió \\
\hline Bicarbonatos $\left(\mathrm{HCO}_{3}^{-}\right)$ & $\mathrm{mg} / \mathrm{L}$ & 164 & no se midió \\
\hline Densidad & $\mathrm{g} / \mathrm{mL}$ & 0,998 & 1,041 \\
\hline
\end{tabular}

\section{Estacionamiento km 45+800}

El talud en LD ubicado en este estacionamiento presenta varios indicios de que está siendo afectado por drenaje ácido. Los problemas encontrados corresponden con alteración química y física del concreto lanzado, pérdida de componente calcáreo en concreto de cunetas, exposición de acero y colapso de concreto lanzado (Fig. 10).

\section{Estacionamiento km 48+000}

En este lugar se realizaron mediciones in situ de $\mathrm{pH}$ de aguas y de $\mathrm{pH}$ en pasta de las rocas alteradas. Los resultados fueron 1,56 y 2,10 respectivamente (Fig. 11). Ambos resultados concuerdan muy bien con los datos obtenidos en el laboratorio, tanto para el muestreo general, como para el muestreo detallado que se realizó en este sitio. 
Todas estas mediciones explican muy bien porqué las cunetas y contra-cunetas están tan alteradas y no hay vegetación en los taludes. La inestabilidad de los taludes de este sitio está directamente relacionada con DAR y se debe de corregir esta situación con las técnicas adecuadas.

\section{CONCLUSIONES}

Con base en los resultados obtenidos en este trabajo, se logró determinar que el estacionamiento $48+000$ presenta DAR, y el estacionamiento 38+700 presenta indicios de este fenómeno en sus aguas, sin embargo es necesario hacer análisis de pasta en las rocas del talud para confirmar con máxima certeza. Como principal mineral generador de acido sulfúrico en los taludes de la ruta, se identificó la pirita, proveniente de la alteración de las lavas andesíticas de Grifo Alto, en conjunto con la gran fracturación presente en esta formación y la alteración hidrotermal de la zona, la exposición óxica al realizar los cortes de carretera, de estas litologías alteradas hidrotermalmente desencadena la oxidación de la pirita. Esta situación afecta directamente las propiedades físicas del concreto lanzado y las cunetas construidas para el manejo de aguas superficiales, ocasionando su colapso y generando un peligro para los usuarios de la carretera. Hay sitios que presentaban indicios de DAR como pátinas de óxidos de hierro, pero los análisis realizados en el laboratorio dieron negativos. Por lo tanto, es muy importante realizar mediciones de $\mathrm{pH}$ en pasta en todos los sitios donde se tengan indicios de que está ocurriendo este proceso (por ejemplo los estacionamientos 38+700 y 45+800), para así poder confirmarlo o descartarlo.

El talud rocoso ubicado en el estacionamiento $45+600$, no presenta DAR. Los problemas de estabilidad del macizo rocoso que se están dando en este sitio específico, no están directamente relacionados con el DAR. Otras variables, como las pendientes tan pronunciadas (en algunos casos verticales), las rocas densamente fracturadas, así como la gran cantidad de agua que atraviesa y baja por ellas, son posiblemente las principales razones que influyen en la generación de problemas de estabilidad y que se traducen en deslizamientos de tipo caídas de bloques.

Los taludes de suelos residuales y roca alterada ubicados en el estacionamiento 48+000, presentan DAR y están influyendo directamente en los problemas de estabilidad de este sitio.

Los valores de $\mathrm{pH}$ del agua estancada en una cuneta del estacionamiento 48+000, coincide con los resultados de los análisis de las muestras de roca, por lo que se reafirma el contenido de DAR en el área.

La geometría y las pendientes $>35^{\circ}$ inciden también en la inestabilidad de los taludes, la sola presencia de DAR no es detonante de inestabilidad, sin embargo afecta considerablemente la pendiente a la que seria estable una estructura. Además, se debe generar un manejo adecuado del agua acida generada por los sitios que presentan DAR debido a su alto contenido de iones mayores y acidez, por su alto potencial de año ambiental.

Según los resultados obtenidos en el estacionamiento del km 48+000 donde se desmostró la presencia de DAR y las relaciones estructurales de posibles fallas tectónicas que se dan en este sitio específico, se considera que el DAR parece tener una fuerte génesis estructural, por lo que para identificar nuevos sitios con presencia de este fenomeno se recomienda realizar un analisis téctonico detallado del area de estudio y en otras zonas.

\section{RECOMENDACIONES}

\section{Recomendaciones generales}

El presente trabajo está orientado en la determinación de DAR en la RN-27. Sin embargo, en busca de una solución a largo plazo y una mejor caracterización del proceso geoquímico, es indispensable realizar un cartografiado geológico a una escala de detalle que permita identificar las litologías de Grifo Alto, con el objetivo de delimitar las zonas con presencia de sulfuros que tengan el potencial de generar DAR con un énfasis gradiente arriba de las líneas de flujo de agua subterránea. 

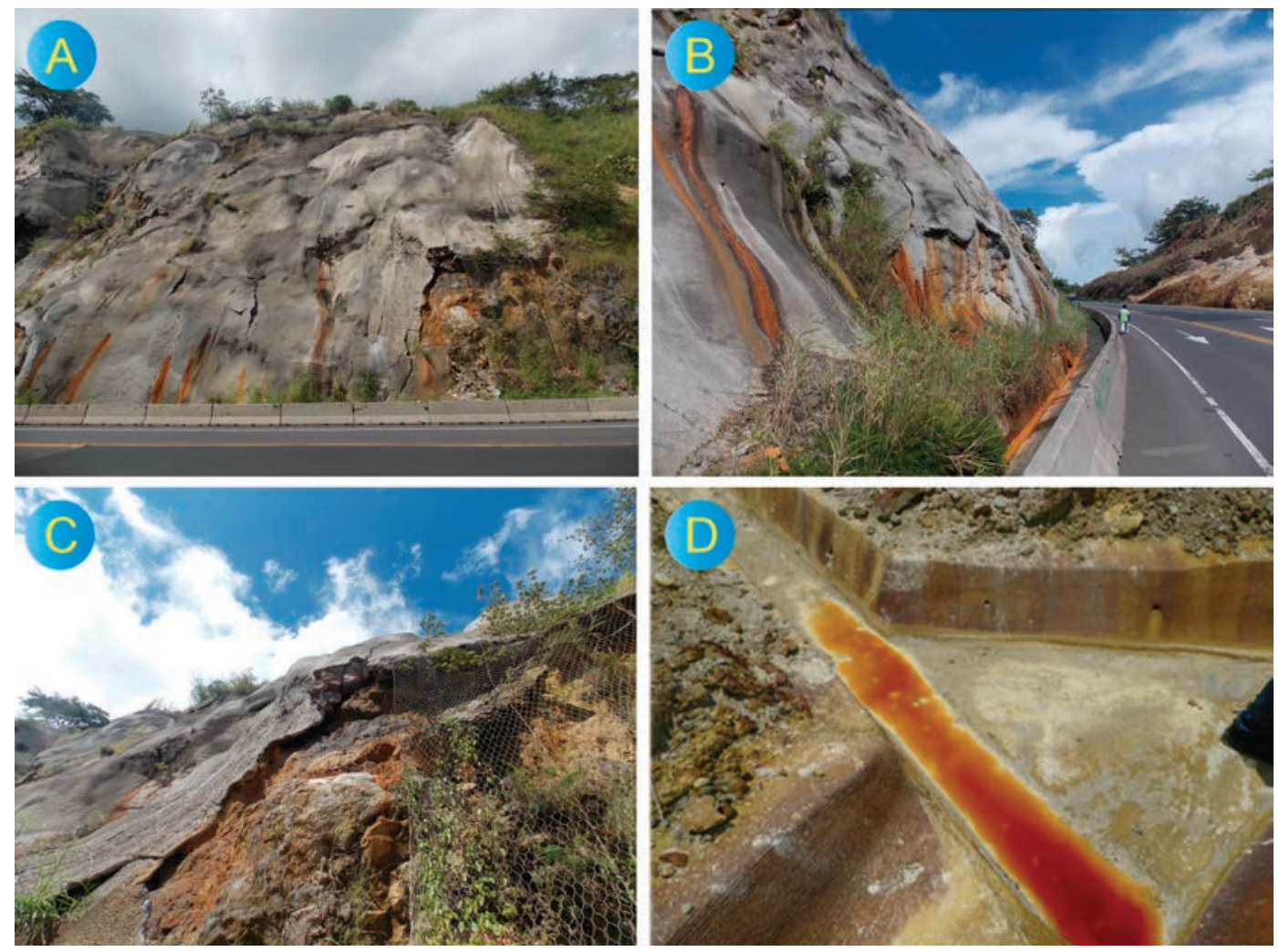

Fig. 10: A) Concreto lanzado con pátinas de óxidos de hierro en la parte inferior. B.) En la parte central se observa la cuneta con acumulación de óxidos de hierro. C) Colapso de concreto lanzado que deja expuesto el acero de las mallas electro-soldadas. D) Acumulación de aguas con coloración rojiza en una cuneta ubicada en la segunda berma del talud LD estacionamiento 48+000 de la RN-27. Nótese los bordes de color blancuzco producto de la reacción del componente calcáreo del cemento de la cuneta y el agua ácida.

Esta propuesta representa un costo económico alto, por lo que se debe considerar su factibilidad en comparación a las posibles remediaciones.

Identificar todos los taludes de la RN-27 que presentan indicios de DAR. Una vez identificados, en cada uno de ellos se sugiere desarrollar un programa de muestreo general y detallado (si lo requiere) de rocas y suelos para realizar pruebas de $\mathrm{pH}$ en pasta como los presentados en este trabajo. Con la información generada se podrá caracterizar cada talud y determinar la mejor solución para asegurar su estabilidad.

Generar e implementar un programa sistemático de monitoreo de medición de $\mathrm{pH}$ de las aguas que salen de los sistemas de drenajes de los taludes caracterizados. Con los datos generados con este programa se podría tener un mejor control y poder determinar la evolución de DAR en los taludes, así como cambios de acidez estacionales entre otros.

Las técnicas empleadas en geoquímica ambiental para controlar DAR en proyectos de minería dependen de qué tan avanzado está el proceso de generación de DAR. En la mayoría de los casos, estas técnicas están enfocas en aislar las rocas que son ricas en sulfuros para así, evitar el contacto con el oxígeno y el agua. Al generar condiciones anóxicas, se reduce la posibilidad de que se forme ácido sulfúrico. Para aislar las rocas, frecuentemente se utilizan, lodos, arcillas y mantas o geomembranas 

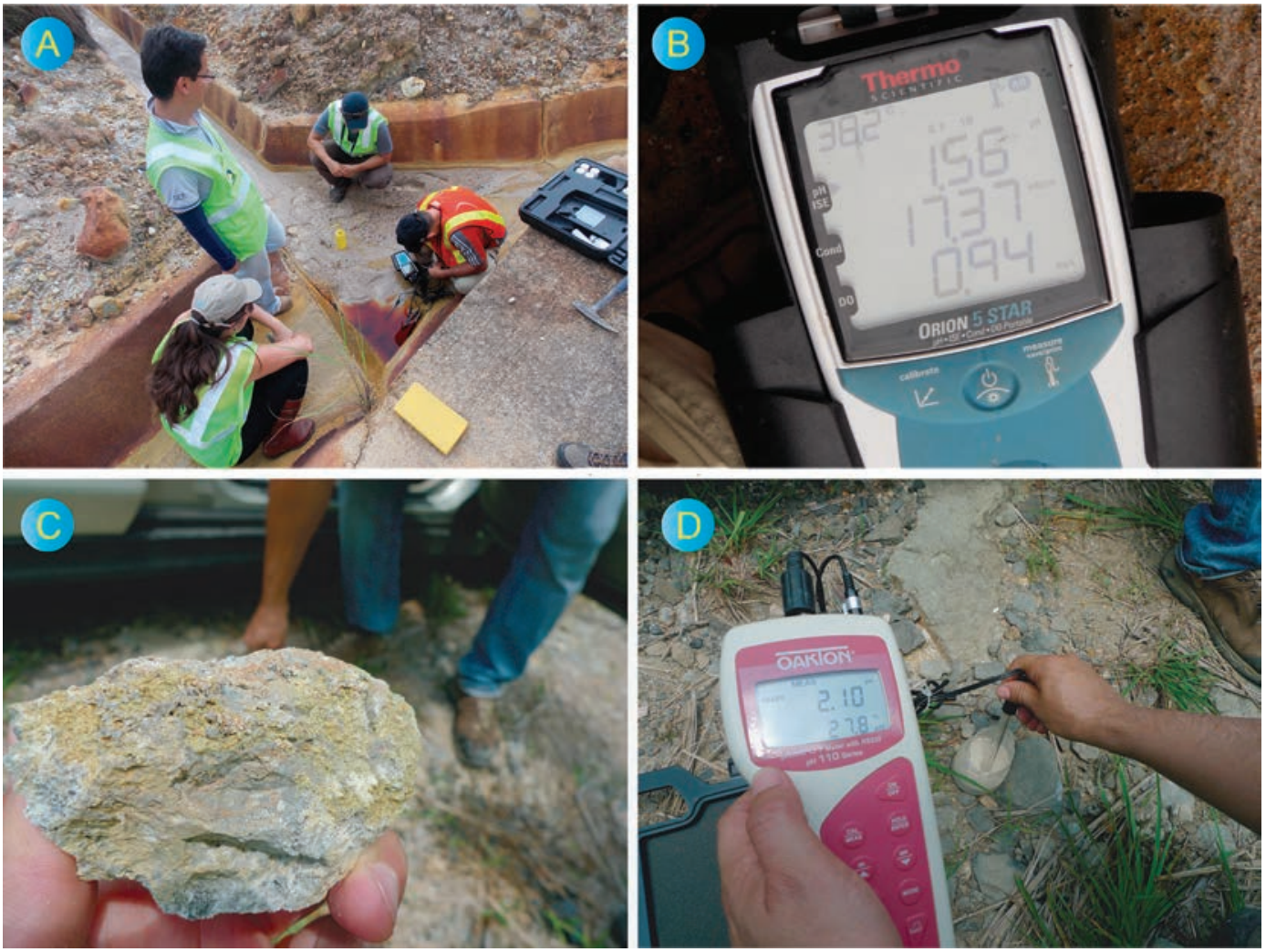

Fig. 11: A.) Se muestra el agua estancada en la cuneta donde se realizó la medición de pH in situ. La coloración rojiza es típica de aguas muy ácidas. B.) Resultado de medición de $\mathrm{pH}$ de agua estancada $(1,56)$ un poco menos que el ácido de batería C.) Muestra de roca alterada con presencia de azufre, con la cual se generó la pasta a la que se le hicieron las mediciones de pH. D.) Resultados de medición de $\mathrm{pH}$ de pasta $(2,1)$.

de recubrimiento con una cobertura de materiales inertes. También se incluyen técnicas para neutralizar la acción del ácido sulfúrico al introducir al sistema, rocas ricas en carbonatos (calizas, dolomitas, margas calcáreas entre otras). Todas estas técnicas tienen que ser consideradas y ver la factibilidad técnica de que sean adaptadas para ser aplicadas en taludes de carreteras.

Hacer análisis geoquímicos de aguas más detallados, en los taludes donde se identifique DAR para determinar cuáles elementos pesados están siendo lixiviados, transportados y entrando al sistema fluvial de la zona.

\section{Recomendaciones para el estacionamiento $45+600$}

Debido a que en este talud no se identificó la presencia de DAR, pero se han presentado problemas de estabilidad (como caída de bloques), se recomienda que se realice una caracterización geotécnica del macizo rocoso que incluya un sistema de clasificación y muestreo de materiales para análisis posterior en el laboratorio de rocas. Una vez caracterizado el talud desde la perspectiva de mecánica de rocas, se podrá determinar la mejor técnica para su estabilización. 
Se recomienda hacer un mapeo geológico detallado que incluya un muestreo de rocas y suelos para análisis de $\mathrm{pH}$ en pasta del sitio ubicado hacia el norte y noroeste de este talud, debido a que existe la posibilidad de que las pátinas de óxidos de hierro y manganeso que presentan las rocas en este sitio, estén relacionadas con un sitio afectado por DAR que se encuentre montaña arriba y que también pueda afectar la línea del ferrocarril que recorre el sector.

\section{Recomendaciones para el estacionamiento 48+000}

Este sitio tiene que ser considerado para que se realice una restauración completa e inmediata de los taludes y que incluya técnicas empleadas para el control de DAR, control de erosión, control de aguas de escorrentía e integración paisajística. Este sitio podría subdividirse en secciones y servir como un laboratorio para probar diferentes metodologías de control de DAR y así determinar cuáles son las más efectivas para un ambiente tropical como el de Costa Rica y la geometría de los taludes de la $\mathrm{RN}-27$.

Además de la restauración, en este sitio, es recomendable que se realice un muestreo en detalle y análisis de $\mathrm{pH}$ en pasta de los suelos y rocas ubicados en las zonas más cercanas al puente sobre el río Salitral y la zona sur, donde se han ido depositando material de escombros. También que se realice un programa de monitoreo constante durante un periodo de al menos un año, donde se hagan mediciones de $\mathrm{pH}$ de las aguas del río Salitral en la parte superior de la cuenca y en el mismo sitio del puente. Se recomienda realizar una evaluación completa del estado del puente y determinar si esta estructura presenta afectación por DAR.

Determinar la profundidad de la zona de afectación por DAR en este sitio. Para esto, se sugiere realizar perforaciones verticales y horizontales en cada una de las bermas de los taludes hasta llegar a la roca sana. Al material recuperado de cada perforación se le deberían de realizar pruebas de $\mathrm{pH}$ en pasta.

\section{AGRADECIMIENTOS}

Se agradece a las personas que participaron en las distintas fases de este informe, especialmente durante el levantamiento de datos, y los análisis de laboratorio. A Fabián Elizondo (Coordinador de laboratorios de LanammeUCR) por facilitar el uso de equipo. A Marcia Cordero (LanammeUCR) por compartir las descripciones de las secciones delgadas del estacionamiento

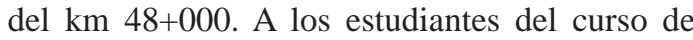
Licenciatura de la ECG, Geoquímica Aplicada, 2014, por la recolección de muestras y análisis en los laboratorios.

\section{REFERENCIAS BIBLIOGRÁFICAS}

ASOCIACIÓN COSTARRICENSE DE GEOTECNIA (ACG), 2010: Reporte de inspección geotécnica de los taludes de corte entre las estaciones $14+000$ a $52+$ 000 Ruta 27 San José - Caldera.- 49 págs. Publicación ACG.0110, San José.

BLOWES, D., PTACEK, C., JAMBOR, J. \& WEISENER, C., 2003: The Geochemistry of Acid Mine Drainage.- Treatiseon Geochemistry, 9: 149-204.

DENYER, P. \& ARIAS, O., 1991: Estratigrafía de la región Central de Costa Rica.- Rev. Geol. Amér. Central, 12: 1-59.

DOLD, B., 2010: Basic Concepts in Environmental Geochemistry of Sulfidic Mine-Waste Management.- En SUNIL, E. (ed.): Waste Management.- Institute 
of Applied Economic Geology (GEA), Universidad de Concepción Chile, 232: 173-198.

GRANDIA, F., SALAS, J., ARCOS, D., ARCHAMBAULT, A. \& COTTARD, F., 2009: Impacto del drenaje ácido de explotaciones mineras en la cuenca del Río Margarita y Embalse de Hatillo (República Dominicana).Bol. Geol. Minero, 120(4): 595-606.

HOLDRIDGE, L. R., 1967: Life zone ecology.206 págs. Tropical Science Center, San José.

MINISTERIO DE ENERGÍA Y MÍNAS DE PERÚ (MEM-PERÚ), 2015: Geoquímica Ambiental, Anexo A: Métodos de análisis. http://intranet2.minem.gob.pe/web/ archivos/dgaam/estudios/tambogrande/ file_001/anexos/11_Anexo\%20XI\%20 Linea\%20Base\%20Geoquimica.pdf. [Consulta: 25 de enero de 2015].

ORNDORFF, Z., DANIELS, L. \& DIAS, L., 2004: Evaluation of Sulfidic Materials in Virginia Highway Corridors.-Environmental Geol., 46(2): 209-216.

PORRAS, H., CASCANTE, M., GRANADOS, R. \& ALVARADO G. E., 2012: Volcanoestratigrafía y tectónica del Valle Central Occidental y las estribaciones de los Montes del Aguacate a lo largo de la Ruta 27, Costa Rica.- Rev. Geol. Amér. Central, 47: 69-93.

SHANKS, P., 2012: Hydrothermal alteration, Volcanogenic Massive Sulfide Occurrence
Model.-345 págs. Scientific Investigation Report 2010-5070-C. U.S. Geological Survey, Virginia.

SLACK, J. F., 1993: Descriptive and Gradetonnage Models for Besshi-type Massive Sulphide Deposits.- En KIRKHAM, R.V., SINCLAIR, W. D., THORPE, R. I.\& DUKE, J. M. (eds): Mineral Deposit Modeling.- Geol. Assoc. Canada. Spec. Paper, 40: 343-371.

SOBEK, A., SCHULLER, W., FREEMAN, J. \& SMITH, R., 1978: Field and Laboratory Methods Applicable to Overburden and Minesoils.- 203 págs. U. S. Environmental Protection Agency (USEPA), Cincinnati, Ohio.

RUIZ, S., 2004: Propuesta de un protocolo para la predicción y evaluación de la generación de drenaje ácido de roca en minas auríferas en explotación.- 83 págs. Univ. de Costa Rica, San José [Tesis Lic.].

UNIDAD DE GESTIÓN Y EVALUACIÓN DE LA RED VIAL NACIONAL (UGERVN), 2014: Informe de Evaluación del Proyecto San José - Caldera, Ruta Nacional 27 Año 2013 - 2014, San José, Costa Rica.- 167 págs. Laboratorio Nacional de Materiales y Modelos Estructurales, San José.

OFFICE OF SOLID WASTE SPECIAL WASTE BRANCH, 1994: Technical Document Acid Mine Drainage Prediction.-52 págs. U. S. Environmental Protection Agency (USEPA), Washington, D.C. 